\title{
A comparison of spermatogenesis in homozygotes, simple Robertsonian heterozygotes and complex heterozygotes of the common shrew (Sorex araneus $L$.)
}

\author{
AGATA BANASZEK, STANISŁAW FEDYK, KATARZYNA A. SZAŁAJ \\ \& WŁODZIMIERZ CHȨTNICKI \\ Institute of Biology, University of Białystok, Świerkowa 20B, 15-950 Białystok, Poland
}

\begin{abstract}
Spermatogenesis was studied in 56 shrews (Sorex araneus L.) from two chromosomal hybrid zones in Poland. The hybrid zones were formed between chromosome races that differed in Robertsonian metacentrics. Shrews were compared in four classes: homozygotes, simple Robertsonian heterozygotes, complex heterozygotes forming four-element rings in meiosis I, and complex heterozygotes forming four- or five-element chains. There was a significant effect of karyotype on the level of germ-cell death and chain-forming complex heterozygotes suffered the greatest germ-cell loss. However, the estimated level of germ-cell death is probably insufficient to influence the fertility of these males.
\end{abstract}

Keywords: chromosome races, common shrew, complex heterozygotes, hybrid zone, Sorex araneus, spermatogenesis.

\section{Introduction}

The common shrew (Sorex araneus L. 1758) shows exceptional chromosome variation at both the intraand interpopulation level. The variability of the common shrew karyotype is based on the occurrence of Robertsonian (centric) fusions and whole-arm reciprocal translocations (see Searle, 1993). Interpopulation chromosome variation manifests itself as the presence of chromosome races, that differ either in the chromosome arm combination of the metacentrics, or the number of these metacentrics relative to the ancestral acrocentric complement (for the list of races see Zima et al., 1996). Metacentrics specific to neighbouring races may show monobrachial homologies relative to one another (i.e. metacentrics have one arm in common). In consequence, interracial hybridization gives rise to hybrids that form chromosome multivalents at prophase I of meiosis. Chromosome multivalents consisting of meta- and acrocentrics form chain $(\mathrm{CH})$ configurations, whereas ring $(\mathrm{R})$ configurations are formed by the metacentrics only.

It is commonly thought that a balance between dispersal and selection against hybrids maintains

*Correspondence. E-mail: banaszek@cksr.ac.bialystok.pl chromosomal hybrid zones. Selection against hybrids results from their lowered fertility caused by the presence of atypical configurations at meiosis I. Meiotic disorders, such as a failure of homologous chromosomes to pair accurately at prophase I and an increased level of nondisjunction at anaphase I, may lead to the greater germ-cell death and postzygotic loss of aneuploid embryos. Pairing irregularities may lead to germ-cell death as a result of inappropriate expression of genes at unpaired regions of autosomes (Miklos, 1974; Burgoyne $\&$ Baker, 1984) or as a consequence of interactions between the sex chromosomes in males and unsynapsed regions of autosomes (Forejt, 1984).

Although the lower fitness of hybrids may be inferred from the structure of many chromosomal hybrid zones (see Searle, 1993; Searle \& Wójcik, 1998), direct data on the fertility of hybrids of the common shrew are still scarce.

This paper presents results of studies on spermatogenesis in male common shrews aimed to establish the relationship between level of germ-cell death and karyotype. The males come from two hybrid zones: one between the Drnholec (Dn) and Lȩgucki Młyn ( $\mathrm{Lg}$ ) chromosome races and another between the Guzowy Młyn $(\mathrm{Gu})$ and $\mathrm{Lg}$ races. The $\mathrm{Dn} / \mathrm{Lg}$ hybrid zone was described incorrectly as the Stobnica/Lg hybrid zone 
(Fedyk et al., 1991; Fedyk, 1995). The change in race classification is caused by a mistake in chromosome arm identification and the incorrect description of chromosome $n r$ specific for the Dn race as chromosome $n p$ (Fedyk et al. unpubl. data). The $\mathrm{Gu} / \mathrm{Lg}$ hybrid zone was initially described as the Drużno/Lg hybrid zone (Banaszek, 1994). The analysis of a larger data set showed that pure populations of the Drużno race were absent from the hybrid zone and that they were replaced by populations of the $\mathrm{Gu}$ race, a karyotypic form of hybrid origin (Banaszek, 1997).

Both hybrid zones are different sections of the same contact zone between the races belonging to the West European karyotypic group (WEKG) and the East European karyotypic group (EEKG) that come into contact in north-eastern Poland (Fedyk, 1995).

\section{Materials and methods}

\section{The animals}

Samples were collected between June and July from 1986 to 1995 in the Dn/Lg hybrid zone, and in 1992-95 in the $\mathrm{Gu} / \mathrm{Lg}$ hybrid zone. Fifty-six males were used for detailed analysis of spermatogenesis: 29 from the $\mathrm{Dn} / \mathrm{Lg}$ hybrid zone, and 27 from the $\mathrm{Gu} / \mathrm{Lg}$ hybrid zone. In addition, as an indicator of spermatogenic performance, the combined testis weight was analysed in 78 karyotyped males (33 from the $\mathrm{Dn} / \mathrm{Lg}$ and 45 from the $\mathrm{Gu} / \mathrm{Lg}$ hybrid zone). The correlation between testis weight and body mass was analysed for a bigger sample of 164 karyotyped and unkaryotyped shrews from these hybrid zones. The samples used for spermatogenesis and for testis weight analyses overlap only in the case of 27 males from the $\mathrm{Gu} / \mathrm{Lg}$ hybrid zone.

The animals were killed and dissected directly after capture. Both testes were weighed to $0.001 \mathrm{~g}$ accuracy and the left testis was fixed in Bouin's solution. As there were no differences in the mean weights of the left and right testes $\left(t_{137}=0.463, P=0.644\right)$, in some cases, where only one testis was weighed, its weight was doubled for the statistical analysis. The animals were weighed to $0.1 \mathrm{~g}$ accuracy. The karyotypes of all individuals were determined from routine spleen preparations (Fedyk, 1980), stained by a G-banding method (Seabright, 1971).

The animals in both samples were subdivided into four categories on the basis of chromosome pairing at meiosis I: homozygotes (bivalents only, except for the sex chromosome trivalent formed by multiple sex chromosomes $\left.\mathrm{XY}_{1} \mathrm{Y}_{2}\right)$, simple Robertsonian $(\mathrm{Rb})$ heterozygotes (one, two or three autosomal trivalents each formed by a metacentric and two homologous acrocentrics), RIV-forming hybrids (ring configuration of four metacentrics) and CHV-forming and CHIV-forming hybrids (chain configuration of three meta- and two acrocentrics and a chain configuration of two meta- and two acrocentrics, respectively). In the common shrew's karyotype the chromosome arms are described by letters according to their length from $a$ (the longest) to $u$ (the shortest) (Searle et al., 1991). Polymorphic chromosome pairs are labelled with a slash (e.g. $m / n$ ) following the nomenclature given by Searle et al. (1991). Homozygotes and simple $\mathrm{Rb}$ heterozygotes belong to the $\mathrm{Dn}$ race (specific metacentrics: $h i, k o, g / m, n / r$ ), Łg race ( $h k, i o, g / r, m / n)$ and $\mathrm{Gu}$ race $(h i, k / o, g / r, m / n)$. Individuals with the $\mathrm{Gu}$ race karyotypes are also present in the $\mathrm{Dn} / \mathrm{Lg}$ hybrid zone; however, they do not form pure populations there and are classified as recombinants. Recombinants are individuals of mixed origin with the metacentrics $h i, k o$ derived from the Dn race and $g r, m n$ from the $\mathrm{Lg}$ race (Fedyk et al., 1991). All the possible types of chromosome complexes are given in Appendix 1. The chromosome composition of complexes in shrews used in this study is the following. The ring (RIV) configuration consists of the same four metacentrics $\left(\mathrm{kh} / \mathrm{hi} / \mathrm{io} / \mathrm{ok}-\mathrm{C}_{1}\right.$ complex $)$ in both hybrid zones. The chain configurations consist of four (CHIV: $r / \mathrm{rg} / \mathrm{gm} / \mathrm{m}$ or $\mathrm{g} / \mathrm{gm} / \mathrm{mn} / \mathrm{n}$ or $\mathrm{m} / \mathrm{mn} / \mathrm{nr} / \mathrm{r}-\mathrm{C}_{2}$ complex) and five elements (CHV: $r / \mathrm{rg} / \mathrm{gm} / \mathrm{mn} / \mathrm{n}-\mathrm{C}_{2}$ complex or $o / o k / k h / h i / i-\mathrm{C}_{1}$ complex) in the Dn/Lg hybrid zone. In the $\mathrm{Gu} / \mathrm{Lg}$ hybrid zone, chain configurations consist of five elements (CHV: $k / k h / h i / i o / o$ or $o / o k / k h / h i / i-\mathrm{C}_{1}$ complex).

\section{Histology and cell counting}

A standard histological protocol was adopted to obtain $10 \mu \mathrm{m}$ paraffin sections. The preparations were stained with haematoxylin and eosin or by the periodic acidSchiff reaction and counterstained with haematoxylin. The $\mathrm{H}+\mathrm{E}$ stained preparations were used to determine the presence or absence of spermatids or spermatozoa in seminiferous tubules. Two perpendicular diameters were measured in 10 seminiferous tubule cross-sections on $\mathrm{H}+$ E preparations and used for the calculation of mean tubular cross-sectional area for each individual. A videocomputer system with frame grabber and css software were used for the measurements. The preparations stained by the PAS technique were used for cell scoring at three stages of the seminiferous epithelium cycle.

Following Mercer et al. (1992) for detailed analysis, the most easily recognized and very characteristic stages II, VI and VIII of the 10-stage seminiferous epithelium cycle (Garagna et al., 1989a) were chosen. Primary pachytene spermatocytes (sc) and round spermatids (sd) were scored at stages II and VI. Only primary spermatocytes were scored at stage VIII, because spermatids 
are elongated and difficult to count at this stage. The cells were scored in five cross-sections of each stage and the Abercrombie (1946) correction was applied. One person made all measurements and counts.

For each individual a mean sc:sd ratio was calculated. If spermatogenesis is not distorted, one would expect a sc:sd ratio of 1:4. Therefore, the sc:sd ratio provides information on germ-cell death during the first meiotic division. The sc:sd ratio was also calculated for separate tubule cross-sections of each individual and the proportion of tubules with substantial germ-cell death was estimated. After Garagna et al. (1989b) the arbitrary limit of the sc:sd ratio less than 1:3 was accepted for 'defective' tubules.

\section{Statistics}

The effects of karyotype, date (months of the breeding season) and place of capture (the hybrid zones $\mathrm{Gu} / \mathrm{Lg}$ and $\mathrm{Dn} / \mathrm{Lg}$ ) were determined by single analysis of variance (ANOVA) and covariance (ANCOVA). Interaction terms (between factors and between factors and covariate) were also tested. As these proved to be statistically nonsignificant, the models without interactions were used. Post-hoc comparisons within sets of means were performed by the protected least-significant difference test (LSD). The means are given with standard errors $( \pm \mathrm{SE})$. Prior to the analysis of variance the data sets were tested for normality with the KolmogorovSmirnov test for goodness of fit. All the data sets fitted a normal distribution. The homogeneity of variances was checked by Bartlett's test.

\section{Results}

The effects of three factors on the combined testis weight were tested: karyotype, the place of capture (the Dn/ $\mathrm{Lg}$ and $\mathrm{Gu} / \mathrm{Lg}$ hybrid zones) and month of capture (June and July) by three-way ANCOVA with body mass as covariate $(n=78)$. Testis weight was correlated with body mass $(r=0.296$, d.f. $=163, P<0.001)$. There were no significant effects of any factor on testis weight. As the effect of karyotype on testis weight was of primary interest, it was additionally tested by single ANCOVA with body mass as covariate; no significant effect of karyotype on testis weight of individuals belonging to different karyotypic groups was found $\left(F_{3,73}=0.517, P=0.672\right)$. Testis weight did not decrease with increasing karyotype complexity (Fig. 1). Also testis weight was not correlated with the sc:sd ratio (in males from the $\mathrm{Gu} / \mathrm{Lg}$ hybrid zone, $r=0.229$, d.f. $=26, P=0.251$ ).

General examination of seminiferous tubules indicated that in all males spermatogenesis proceeded without major disruption and spermatozoa (stages $\mathrm{I}-\mathrm{V}$ of

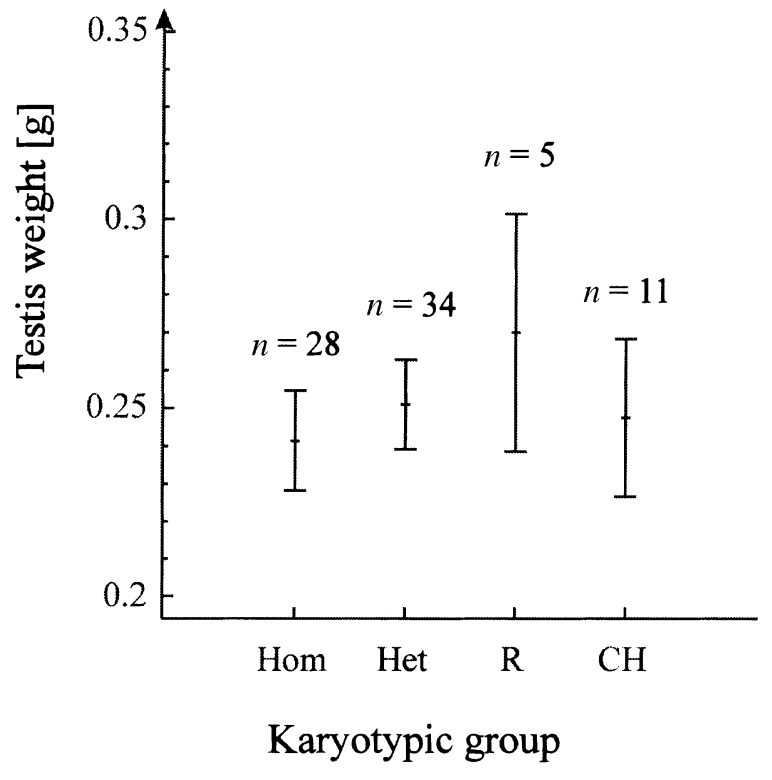

Fig. 1 Testis weight $( \pm \mathrm{SE})$ in homozygous (Hom), simple $\mathrm{Rb}$ heterozygous (Het), ring-forming ( $\mathrm{R}$ ) and chain-forming $(\mathrm{CH})$ complex heterozygous male Sorex araneus from the $\mathrm{Dn} / \mathrm{Lg}$ and $\mathrm{Gu} / \mathrm{Lg}$ hybrid zones.

seminiferous epithelium cycle) or spermatids (stages VI-X) were present in all tubules.

There were no significant differences in the mean area of tubule cross-section of individuals belonging to different karyotypic groups and caught in different months of the breeding season (ANOVA; $F_{3,50}=0.640$, $P=0.593 ; F_{1,50}=0.183, P=0.676$, respectively). However, the mean area of tubule cross-section in males from the $\mathrm{Dn} / \mathrm{Lg}$ hybrid zone $\left(1.096 \pm 0.031 \mathrm{~mm}^{2}\right)$ was significantly greater than in males from the $\mathrm{Gu} / \mathrm{Lg}$ hybrid zone $\left(0.960 \pm 0.037 \mathrm{~mm}^{2}\right) \quad$ (ANOVA; $F_{1,50}=$ 7.407, $P=0.009$ ). To compare individuals from different hybrid zones the numbers of primary spermatocytes and spermatids were recalculated per $100 \mu \mathrm{m}^{2}$ area (Table 1) and the sc:sd ratio was determined.

The effect of karyotype on the sc:sd ratio was tested by two-way ANOVA in 56 males collected in both hybrid zones in June and July; in these months the sc:sd ratio did not vary significantly (ANOvA; $F_{1,54}=2.028, P=$ 0.160 ). There was a significant effect of karyotype and place of capture on the sc:sd ratio (ANOVA; $F_{3,51}=7.262$, $P<0.001 ; \quad F_{1,51}=17.978, \quad P<0.001$, respectively). Chain-forming hybrids had a sc:sd ratio lower than homozygotes and simple Rb heterozygotes (Fig. 2); this was significant with the LSD test. The sc:sd ratio of chain-forming hybrids was also lower than that of ringforming hybrids, but this difference was not statistically significant. Ring-forming hybrids had a sc:sd ratio significantly lower than simple $\mathrm{Rb}$ heterozygotes. In 
Table 1 Mean numbers of primary spermatocytes (sc) and spermatids (sd) per $100 \mu \mathrm{m}^{2}$ of cross-section of seminiferous tubule and proportion of 'defective' tubules $( \pm \mathrm{SE})$ in male Sorex araneus belonging to different karyotypic groups from the $\mathrm{Dn} / \mathrm{Lg}$ and $\mathrm{Gu} / \mathrm{Lg}$ hybrid zones

\begin{tabular}{|c|c|c|c|c|c|c|c|c|}
\hline \multirow[b]{2}{*}{ Karyotypic group } & \multicolumn{4}{|c|}{$\mathrm{Dn} /$ Lg hybrid zone } & \multicolumn{4}{|c|}{$\mathrm{Gu} / \mathrm{Lg}$ hybrid zone } \\
\hline & $n$ & sc number* & sd number* & $\begin{array}{l}\text { 'Defective' } \\
\text { tubules [\%] }\end{array}$ & $n$ & sc number* & sd number* & $\begin{array}{l}\text { 'Defective' } \\
\text { tubules [\%] }\end{array}$ \\
\hline $\mathrm{H}$ & 7 & 4.75 & $51 \pm 13.80$ & 86 & 5 & 51.16 & $71 \pm 16$ & 22.0 \\
\hline Het & 12 & $0 \pm 3.62$ & $3 \pm 1$ & 11.7 & 12 & $6=$ & $99 \pm$ & 32. \\
\hline RIV & 6 & $39.10 \pm 5.13$ & $127.71 \pm 14.90$ & $11.7 \pm 7.8$ & 4 & $52.93 \pm 6.28$ & $160.74 \pm 18.25$ & $45.0 \pm 9.5$ \\
\hline $\mathrm{CHIV}$ and $\mathrm{CHV}$ & 4 & $39.18 \pm 6.28$ & $119.96 \pm 18.25$ & $37.5 \pm 9.5$ & 6 & $53.58 \pm 5.13$ & $152.26 \pm 14.90$ & $61.7 \pm 7.8$ \\
\hline
\end{tabular}

*The difference in mean numbers of primary spermatocytes and spermatids between the males coming from different hybrid zones results from the recalculation of the germ cell numbers per $100 \mu \mathrm{m}^{2}$ area of cross-section of seminiferous tubule.

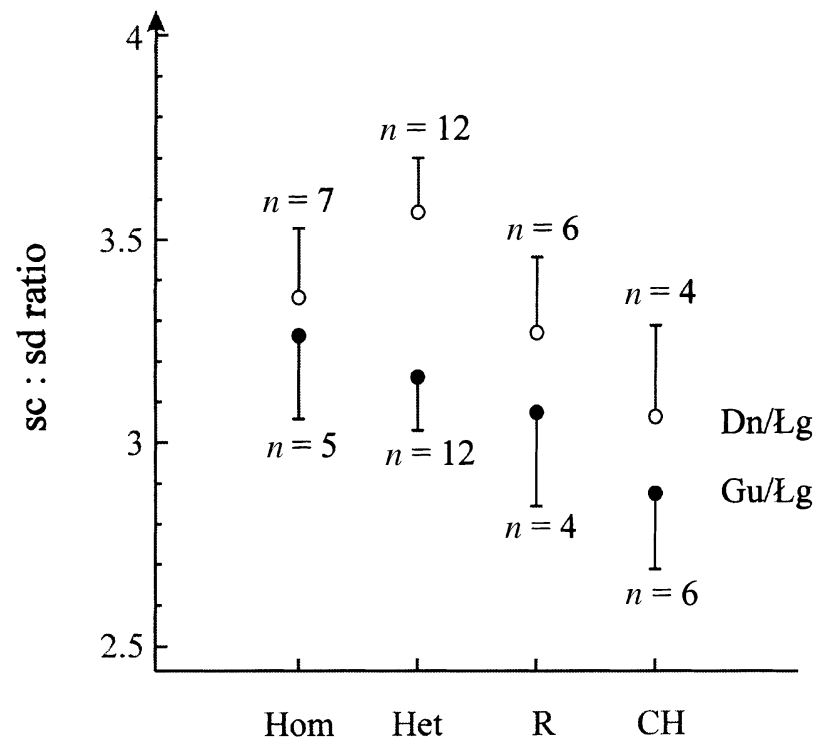

Karyotypic group

Fig. 2 A comparison of the mean sc:sd ratio $( \pm \mathrm{SE})$ in male Sorex araneus of the same karyotypic group - homozygotes (Hom), simple Rb heterozygotes (Het), ring-forming hybrids (R) and chain-forming hybrids $(\mathrm{CH})$ - from the $\mathrm{Dn} / \mathrm{Lg}$ and $\mathrm{Gu} / \mathrm{Lg}$ hybrid zones.

general, all males from the $\mathrm{Dn} / \mathrm{Lg}$ hybrid zone had higher sc:sd ratios $(3.31 \pm 0.04)$ than males caught in the $\mathrm{Gu} / \mathrm{Lg}$ hybrid zone (3.06 \pm 0.05$)$. Nevertheless, the tendencies were similar in both zones; the sc:sd ratio decreased from values characteristic for individuals of pure races (homozygotes and simple $\mathrm{Rb}$ heterozygotes) through ring-forming hybrids to the lowest values in chain-forming hybrids (Fig. 2). The only clear difference between the hybrid zones was that simple Rb heterozygotes had a higher sc:sd ratio than homozygotes in the $\mathrm{Dn} / \mathrm{Lg}$ hybrid zone, whereas in the $\mathrm{Gu} / \mathrm{Lg}$ hybrid zone homozygotes had the highest sc:sd ratio.
The proportion of 'defective' tubules was closely correlated with the sc:sd ratio $(r=0.823$, d.f. $=55$, $P<0.001)$. Likewise the proportion of 'defective' tubules varied significantly with karyotype and the place of capture (ANOvA; $F_{3,51}=6.806, \quad P<0.001$; $F_{1,51}=19.028, P<0.001$, respectively). Chain-forming hybrids had the highest proportion of 'defective' tubules (Table 1) and differed significantly from individuals of other karyotypic groups. The differences between homozygotes, simple $\mathrm{Rb}$ heterozygotes and ring-forming hybrids were not statistically significant. However, all males from the $\mathrm{Gu} / \mathrm{Lg}$ hybrid zone had more 'defective' tubules (39.8\%) than males from the Dn/ $\mathrm{Lg}$ hybrid zone (17.8\%).

There was no difference in the sc:sd ratio between the shrews of the Dn, $\mathrm{Lg}$ races and recombinants in the Dn/ Łg hybrid zone (ANOvA; $F_{2,16}=0.009, P=0.991$ ) and between shrews of the $\mathrm{Gu}$ and $\mathrm{Lg}$ races in the $\mathrm{Gu} / \mathrm{Lg}$ hybrid zone (ANOvA; $F_{1,15}=0.346, P=0.571$ ).

\section{Discussion}

Amongst the shrews from the $\mathrm{Dn} / \mathrm{Lg}$ and $\mathrm{Gu} / \mathrm{Lg}$ hybrid zones, there was no evidence that simple $\mathrm{Rb}$ heterozygotes had reduced fertility relative to homozygotes. Homozygotes and simple $\mathrm{Rb}$ heterozygotes did not differ significantly in their sc:sd ratios (Fig. 2) and proportion of 'defective' tubules (Table 1). The mean sc:sd ratio for simple $\mathrm{Rb}$ heterozygotes tended to be even higher, especially in the Dn/Lg hybrid zone, than for homozygotes (Fig. 2). Garagna et al. (1989b) also did not find significant differences in the sc:sd ratio between homozygotes and simple $\mathrm{Rb}$ heterozygotes collected from the vicinity of the hybrid zone between the Oxford and Hermitage chromosome races in Britain, although simple $\mathrm{Rb}$ heterozygotes tended to have lower values of the sc:sd ratio. The lack of clear differences in the level of germ-cell death between homozygotes and simple $\mathrm{Rb}$ heterozygotes is not surprising, as in meiosis 
of the common shrew trivalents pair very regularly and only $8 \%$ of cells show unpairing around the centromere at pachytene (Wallace \& Searle, 1990). Moreover, there is no substantial increase in the degree of contact between autosomes and sex chromosome trivalents in heterozygotes over that in homozygotes (Wallace \& Searle, 1990).

With regard to sc:sd ratio and proportion of 'defective' tubules, males with chain configurations suffered from the highest germ-cell loss, whereas ring-forming hybrids had an intermediate position between chainforming hybrids and individuals of pure races (homozygotes and simple $\mathrm{Rb}$ heterozygotes) (Table 1, Fig. 2). In general, ring configurations clearly caused less meiotic disturbance than chain configurations. Likewise, Narain \& Fredga (1997) failed to find significant differences in the incidence of germ-cell death between ring-forming hybrids (RIV) and homozygotes collected in the hybrid zone between the Uppsala and Hallefors races in Sweden. Also Garagna et al. (1989b) found that CHIV-forming hybrids from the Oxford/Hermitage hybrid zone tended to have higher germ-cell loss than homozygotes and simple $\mathrm{Rb}$ heterozygotes, although the differences between those karyotypic groups were not statistically significant.

The most important question is, whether the poorer spermatogenic performance of hybrid individuals compared with homozygotes and simple $\mathrm{Rb}$ heterozygotes may cause a reduction of their fertility. Garagna et al. (1989b), on the basis of sperm-count values, stated that all the males they studied were fully fertile. Although we did not carry out sperm counts, it seems that the level of spermatogenesis disruption was also minimal; in chainforming hybrids the sc:sd ratio was 2.97 and in ringforming hybrids it was higher (3.16). This assumption is supported by the lack of clear differences in testis weight between males belonging to different karyotypic groups (Fig. 1). A substantially increased level of germ-cell death should be reflected in lower testis weights, as was found in heterozygous mice Mus musculus domesticus (Searle \& Beechey, 1974) and common shrews with numerical chromosome aberrations (Searle, 1984; Searle \& Wilkinson, 1986). Garagna et al. (1989b) found that CHIV-forming hybrids had a significantly lower testis weight than simple $\mathrm{Rb}$ heterozygotes. Moreover, the sc:sd ratio and testis weights in hybrids were correlated (Garagna et al., 1989b), although the estimation was based on four individuals and therefore potentially subject to error. We did not find such relationships in males from the $\mathrm{Dn} / \mathrm{Lg}$ and $\mathrm{Gu} / \mathrm{Lg}$ hybrid zones. Testis weight did not depend on karyotype (Fig. 1) and was not correlated with the sc:sd ratio. A higher level of germ-cell loss could also influence the cross-sectional area of seminiferous tubules. However, there was no relation- ship between the area of tubule cross-sections and karyotype. The area of tubule cross-sections was lower in males from the $\mathrm{Gu} / \mathrm{Lg}$ than from $\mathrm{Dn} / \mathrm{Lg}$ hybrid zone. This indicates general differences in the spermatogenic performance of males from different areas. All males from the Dn/ $\mathrm{Lg}$ hybrid zone had significantly higher sc:sd ratios than males caught in the $\mathrm{Gu} / \mathrm{Lg}$ hybrid zone (Fig. 2). We do not know the reason for this difference. We have no independent evidence of greater genetic differences between the $\mathrm{Gu}$ and $\mathrm{Lg}$ than between the Dn and $\mathrm{Lg}$ chromosome races (see Chętnicki et al., 1996). In this study we found no clear differences in spermatogenic performance between individuals of pure races.

The substantial individual variation of the sc:sd ratio observed by Garagna et al. (1989b) prompted them to assume that chain-forming hybrids in the common shrew could have a greater predisposition to sterility, similar to heterozygotes for $\mathrm{Rb}$ metacentric $\mathrm{t}(14 ; 21)$ in man, where individuals may range from fully fertile to sterile (Rosenmann et al., 1985). Garagna et al. (1989b) stated that even a marginally greater proportion of sterile males among hybrids than among individuals of pure races would be sufficient to influence the gene flow between hybridizing races. However, this assumption is weakened by the lack of severe disruption of spermatogenesis in males studied to date.

Thus, the estimated level of germ-cell loss is probably not sufficient to reduce the fertility of hybrids. So it is rather surprising that the presence of chromosomal multivalents in meiosis causes only minor disorders in spermatogenesis of the common shrew. As spermatogenic disorders result from errors in chromosomal pairing (Miklos, 1974; Burgoyne \& Baker, 1984; Forejt, 1984), it has to be assumed that chromosome pairing in heterozygous complexes is very regular in the common shrew. Indeed, a direct analysis of chromosome pairing at pachytene and diakinesis supports this assumption. For example, the frequency of univalence scored at diakinesis in complex heterozygotes was very low and there were no univalents from chromosomal complexes, either in CHIV-forming hybrids from the Oxford/ Hermitage hybrid zone (Searle, 1986; Mercer et al., 1991), or in CHV-forming hybrids from the $\mathrm{Gu} / \mathrm{Lg}$ hybrid zone (Banaszek, 1997). Furthermore, the frequency of associations between heterozygous complexes and the sex chromosome trivalent was low (Searle, 1986; Banaszek, unpubl. data). In CHVII-forming hybrids obtained from laboratory crosses of shrews belonging to the Oxford and Aberdeen races, there were only 33\% of cells with fully synapsed chain complexes at pachytene whereas at diakinesis just $1.6 \%$ of chain configurations showed incomplete synapsis (Mercer et al., 1992). Mercer et al. (1992) were not able to substage pachytene spreads accurately, but they suggested that the majority 
of cells showing asynapsis became fully synapsed in late pachytene. Moreover, at pachytene and at diakinesis there were only infrequent associations between the sex trivalent and chain VII configurations (13\% and $6 \%$ of cells, respectively; Mercer et al., 1992). In RIV-forming hybrids from the Uppsala/Hallefors hybrid zone, 58\% of cells in pachytene showed a broken ring configuration, but as the hybrids did not suffer from any substantial germ cell death, the defective cells must produce completely viable spermatozoa (Narain \& Fredga, 1997). Interactions between the ring configuration and sex trivalent were extremely rare and occurred in only $2 \%$ of cells (Narain \& Fredga, 1997).

Even if chain-forming hybrids finish their breeding season earlier than individuals of pure races, because of the higher level of germ-cell death, it does not have to impair their reproductive success. The majority of births (usually three litters) occur between May and July in Britain (Searle \& Stockley, 1994). Under Polish climatic conditions the breeding season may be longer, with more litters (up to five) in some years. However, the reproductive potential of females clearly reduces with age. The numbers of nonreproducing females increase in August, and those that are pregnant have greater foetal loss (Tarkowski, 1957). Thus the reproductive success of an individual probably does not depend on its ability to reproduce at the end of the breeding season.

Therefore, selection against hybrids, especially chainforming ones, as can be inferred from the chromosomal structure of many hybrid zones in the common shrew (see Searle, 1993; Searle \& Wójcik, 1998), is unlikely to be the result of a lowered number of gametes. Likewise the hypothesis of selective advantage of ring-forming hybrids over chain-forming hybrids (Fedyk et al., 1991) cannot be supported on the basis of the present paper. Germ-cell loss caused by the presence of chain configurations at meiosis was greater than by ring ones. However, it probably did not influence the fertility of hybrids. It seems that selection against those hybrids can be caused only by the lower quality, not by the smaller numbers, of gametes produced by hybrids. Lower fertility of those males and also possible differences between chain-forming and ring-forming hybrids may result from a higher level of nondisjunction and, as a consequence, a loss of aneuploid embryos.

\section{Acknowledgements}

We are grateful to Dr A. Krasowska, Dr M. Ratkiewicz, A. Busłowska, M. Romanowska and M. Kozioł for their help in field and laboratory work. We thank Dr Marek Konarzewski and Dr Jeremy B. Searle for valuable comments and revising the English style of the manuscript. This work was supported by grants 6P204 03405 and 6P04C 03515 of the Polish State Committee of Scientific Research.

\section{References}

ABERCROMBIE, M. 1946. Estimation of nuclear population from microtome sections. Anat. Rec., 94, 239-247.

BANASZEK, A. 1994. The structure of the contact zone between chromosomal races Drużno and Łęgucki Młyn in the common shrew (Sorex araneus) in north-eastern Poland preliminary results. Folia Zool., 43 (Suppl. 1), 11-19.

BANASZEK, A. 1997. Chromosome Variation and Breeding Parameters of the Common Shrew (Sorex araneus L., 1758) in an Interracial Hybrid Zone. PhD Thesis, University of Warsaw [in Polish].

BURGOYNE, P. S. AND BAKER, T. G. 1984. Meiotic pairing and gametogenetic failure. In: Evans, C. W. and Dickinson, H. G. (eds) Controlling Events in Meiosis, pp. 349-362. 38th Symp. Soc. Exp. Biol. Company of Biologists, Cambridge.

CHȨTNICKI, W., FEDYK, S., BANASZEK, A., SZAŁAJ, K. A. AND RATKIEWICZ, M. 1996. Morphometrical characteristics of the common shrew (Sorex araneus L.) from interracial hybrid zones. Hereditas, 125, 201-208.

FEDYK, S. 1980. Chromosome polymorphism in a population of Sorex araneus L. at Białowieża. Folia Biol., 28, 83-120.

FEDYK, s. 1995. Geographic Chromosomal Differentiation and Hybrid Zones between Chromosome Races of Sorex araneus in North-eastern Poland. Dissertationes Universitatis Varsoviensis 439, Białystok [in Polish].

FEDYK, S., CHEsTNICKI, W. AND BANASZEK, A. 1991. Genetic differentiation of Polish populations of Sorex araneus L. III. Interchromosomal recombination in a hybrid zone. Evolution, 45, 1384-1392.

FOREJT, J. 1984. X-inactivation and its role in male sterility. Chromosomes Today, 8, 117-127.

GARAGNA, S., ZUCCOTti, M., SEARle, J. B. AND REDI, C. A. 1989a. Histological description of the seminiferous epithelium cycle in the common shrew (Sorex araneus L.). Boll. Zool., 56, 299-303.

GARAGNA, S., ZUCCOTTI, M., SEARle, J. B., REDI, C. A. AND WILKINSON, P. J. 1989b. Spermatogenesis in heterozygotes for Robertsonian chromosomal rearrangements from natural populations of the common shrew, Sorex araneus. J. Reprod. Fert., 87, 431-438.

MERCER, S. J., SEARle, J. B. AND WALlACE, B. M. N. 1991. Meiotic studies of karyotypically homozygous and heterozygous male common shrews. Mém. Soc. Vaud. Sc. Nat., 19, $33-43$.

MerCer, S. J., WALlace, B. M. N. AND SEARle, J. B. 1992. Male common shrews (Sorex araneus) with long meiotic chain configurations can be fertile: implications for chromosomal models of speciation. Cytogenet. Cell Genet., 60, 68-73.

MIKLOS, G. L. G. 1974. Sex chromosome pairing and male fertility. Cytogenet. Cell Genet., 13, 558-577.

NARAIN, Y. AND FREDGA, K. 1997. Meiosis and fertility in common shrews, Sorex araneus, from a chromosomal 
hybrid zone in central Sweden. Cytogenet. Cell Genet., 78, 253-259.

ROSEnMANN, A., WAHRMAN, J., RICHLER, C., VOSS, R., PERSiTZ, A. AND GOLDMAN, B. 1985. Meiotic association between the XY chromosomes and unpaired autosomal elements as a cause of human male sterility. Cytogenet. Cell Genet., 39, 19-29.

SEABRIGHT, M. 1971. A rapid banding technique for human chromosomes. Lancet, 2, 971-972.

SEARLE, A. G. AND BEECHEY, C. V. 1974. Sperm count, eggfertilization and dominant lethality after X-irradiation of mice. Mutation Res., 22, 63-72.

SEARLE, J. B. 1984. A wild common shrew (Sorex araneus) with an XXY sex chromosome constitution. J. Reprod. Fert., 70, $353-356$.

SEARLE, J. B. 1986. Meiotic studies of Robertsonian heterozygotes from natural populations of the common shrew, Sorex araneus L. Cytogenet. Cell. Genet., 41, 154-162.

SEARle, J. B. 1993. Chromosomal hybrid zones in eutherian mammals. In: Harrison, R. G. (ed.) Hybrid Zones and the Evolutionary Process, pp. 309-353. Oxford University Press, New York.

SEARLE, J. B. AND STOCKLEY, P. 1994. The breeding system of the common shrew (Sorex araneus) from a genetical perspective. Folia Zool., 43 (Suppl. 1), 97-105.
SEARLE, J. B. AND WILKINSON, P. J. 1986. The XYY condition in a wild mammal: an XY/XYY mosaic common shrew (Sorex araneus). Cytogenet. Cell Genet., 41, 225-233.

SEARLE, J. B. AND wósciK, J. M. 1998. Chromosomal evolution: The case of Sorex araneus. In: Wójcik, J. M. and Wolsan, M. (eds) Evolution of Shrews, pp. 219-268. Mammal Research Institute, Polish Academy of Sciences, Białowieża.

SEARLE, J. B., FEDYK, S., FREDGA, K., HAUSSER, J. AND volobouev, v. T. 1991. Nomenclature for the chromosomes of the common shrew (Sorex araneus). Mém. Soc. Vaud. Sci. Nat., 19, 13-22.

TARKOWSKI, A. K. 1957. Studies on reproduction and prenatal mortality of the common shrew (Sorex araneus L.). II. Reproduction under natural conditions. Ann. Univ. M. Curie - Skłodowska, 8C, 177-244 [in Polish, with English summary].

WAllace, B. M. N. AND SEARle, J. B. 1990. Synaptonemal complex studies of the common shrew (Sorex araneus). Comparison of Robertsonian heterozygotes by light microscopy. Heredity, 65, 359-367.

ZIMA, J., FEDYK, S., FREDGA, K., HAUSSER, J., MISHTA, A., SEARLE, J. B. ET AL. 1996. The list of the chromosome races of the common shrew (Sorex araneus). Hereditas, 125, 97-107. 


\section{Appendix 1}

a)
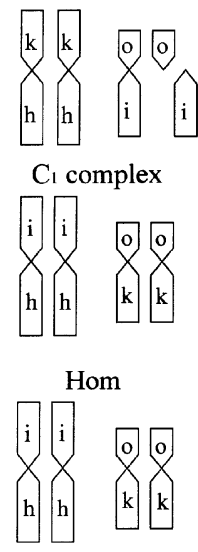

b)

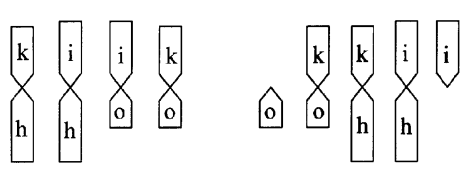

c)

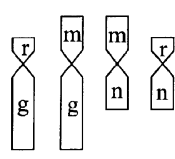

d)

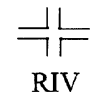

n
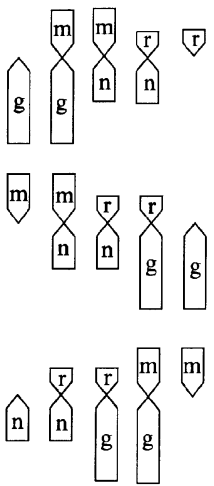

(r)

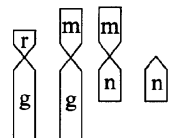

$\underset{\mathrm{CHV}}{\Perp}$
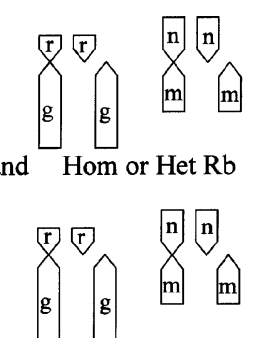

$\mathrm{C}_{2}$ complex

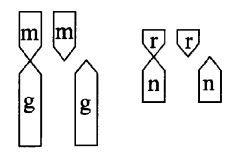

Drnholec race
Łęgucki Młyn race

$C_{1}$ hybrids

Recombinants

$\mathrm{C}_{2}$ hybrids

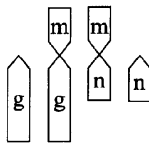

กิ $\hat{r}$
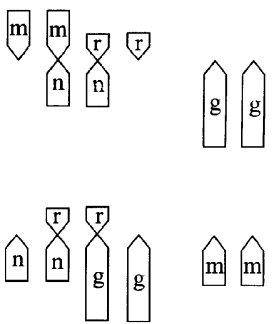

r)

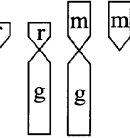

n $\mathrm{n}$

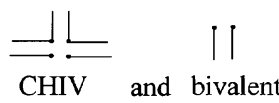

The types of hybrids present in the $\mathrm{Dn} / \mathrm{Lg}$ and $\mathrm{Gu} / \mathrm{Lg}$ hybrid zones of Sorex araneus. (a) Schematic representation of the most common crosses giving rise to hybrids in the $\mathrm{Dn} / \mathrm{Lg}$ hybrid zone. The individuals of the $\mathrm{Dn}, \mathrm{Lg}$ race and recombinants are shown as simple $\mathrm{Rb}$ heterozygotes with respect to polymorphic pairs of chromosomes. The recombinants are the most common category of individuals in the centre of the hybrid zone. The crosses between recombinants and shrews of the $\mathrm{g}$ race give rise to hybrids with $\mathrm{C}_{1}$ meiotic complex. $\mathrm{C}_{1}$ hybrids are homozygotes or simple $\mathrm{Rb}$ heterozygotes with respect to $g r$ and $m n$ pairs of chromosomes that are specific for both recombinants and shrews of the $\mathrm{lg}$ race. The crosses between recombinants and shrews of the $\mathrm{Dn}$ race give rise to hybrids with $\mathrm{C}_{2}$ meiotic complex. $\mathrm{C}_{2}$ hybrids are homozygotes with respect to $h i$ and $k o$ chromosome pairs. The crosses between shrews of the $\mathrm{gg}$ and Dn races give rise to hybrids with two independent meiotic complexes $\mathrm{C}_{1}$ and $\mathrm{C}_{2}$. These hybrids are extremely rare in the hybrid zone due to high frequencies of recombinants (Fedyk et al., 1991). (b) chromosome composition of $\mathrm{C}_{1}$ complex. (c) chromosome composition of $\mathrm{C}_{2}$ complex. The $\mathrm{C}_{2}$ chromosome complex is highly variable due to polymorphism of all chromosome pairs forming this complex. In the case of CHV and CHIV configurations of $\mathrm{C}_{2}$ complex different chromosome arms may occur as acrocentrics. If the $\mathrm{C}_{2}$ complex is of CHIV configuration, one pair of acrocentrics is excluded from the complex and forms independent bivalent in meiosis I. (d) meiotic configurations of $\mathrm{C}_{1}$ and $\mathrm{C}_{2}$ complexes at pachytene stage: RIV — four-element ring configuration or CHV — five-element chain configuration or CHIV - fourelement chain configuration. The chromosomal structure of the $\mathrm{Gu} / \mathrm{Lg}$ hybrid zone generally corresponds to the part of the $\mathrm{Dn} / \mathrm{Lg}$ hybrid zone, e.g. the crosses between the recombinants (the Gu race) and shrews of the $\mathrm{Lg}$ race. The only difference is the polymorphism of $k o$ chromosome pair which results in the presence of one more type of $\mathrm{C}_{1}$ hybrid with CHV configuration $-k / k h / h i / i o / o$ (Banaszek, 1994). 